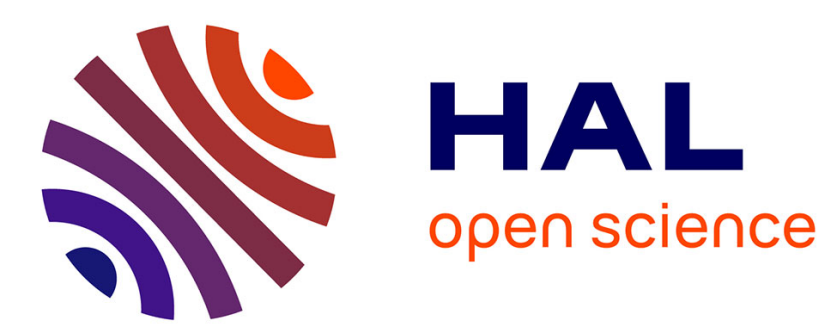

\title{
Distributed Simulation Platform to Design Advanced RFID based Freight Transportation Systems
} Gregory Zacharewicz, Jean-Christophe Deschamps, Julien Francois

\section{To cite this version:}

Gregory Zacharewicz, Jean-Christophe Deschamps, Julien Francois. Distributed Simulation Platform to Design Advanced RFID based Freight Transportation Systems. Computers in Industry, 2011, 62 (6), pp.597-612. 10.1016/j.compind.2011.04.009 . hal-00588338

\section{HAL Id: hal-00588338 https://hal.science/hal-00588338}

Submitted on 24 May 2016

HAL is a multi-disciplinary open access archive for the deposit and dissemination of scientific research documents, whether they are published or not. The documents may come from teaching and research institutions in France or abroad, or from public or private research centers.
L'archive ouverte pluridisciplinaire HAL, est destinée au dépôt et à la diffusion de documents scientifiques de niveau recherche, publiés ou non, émanant des établissements d'enseignement et de recherche français ou étrangers, des laboratoires publics ou privés. 


\title{
DISTRIBUTED SIMULATION PLATFORM TO DESIGN ADVANCED RFID BASED FREIGHT TRANSPORTATION SYSTEMS
}

\author{
Gregory ZACHAREWICZ, Jean-Christophe DESCHAMPS, Julien FRANCOIS \\ LABORATOIRE IMS-LAPS UMR CNRS 5218 GROUPE PRODUCTIQUE (GRAI) \\ 351 Cours de la Libération \\ 33405 Talence Cedex, France \\ \{gregory.zacharewicz, jean-christophe.deschamps, julien.francois\}@ims-bordeaux.fr
}

\begin{abstract}
RFID systems known to improve supply chains performances are not well-implemented in industry, particularly in the field of transport, due to the high economic investment it requests in comparison to other existing solutions. However, their benefits may be theoretically proved by using a distributed simulation platform to support the design and test of any technical solution and organisational approach devoted to optimize RFID-based logistics systems. This paper deals with the development of this simulation platform, based on G-DEVS (Generalized Discrete Event Specification) models and HLA (High Level Architecture) standard. The different partner's components of the networked logistics enterprise are described. The proposed solution is applied to a freight transportation system and emulates the behaviour of the various components (RFID coupled to geolocation and mobile technology) required to optimise the products routing. The behaviour of the main components is G-DEVS formalized including the logistics supplier server, the smart product and the vehicle onboard device to interface the products with a centralized server. Delivery scenarios are then elaborated and simulated to check the behavior and the level of communication network utilization between distributed G-DEVS models and other simulation components. The strength of the approach lies in the interoperability of the platform to simulate scenarios including discrete event models and real hardware and software devices via an HLA connection. From these results a discussion is given to validate or reject the conceptual choices about logistics components behavior and their theoretical network solicitation level regarding GSM, GPRS, Bluetooth and RFID networks capacity.
\end{abstract}

KEYWORDS: Logistics, RFID, Discrete Event Modeling, DEVS, G-DEVS, Distributed Simulation, HLA.

\section{INTRODUCTION}

Supply Chain Management (SCM) is an approach to coordinate materials and information flows between business entities in fulfilling customer's demand. The SCM dilemma is that Supply Chain (SC) processes are ever more interdependent while SC members try to keep their economic independency and decision-making autonomy. The coordination challenge lies in connecting the appropriate part of business partners' information systems involved in a SC. A global issue in SCM is then to develop data exchange mechanisms to align the objectives of independent supply chains members and coordinate their decisions and activities to optimize the whole system performance.

Coordination becomes more efficient when SC partners transmit accurate, complete, and consistent information about products through the supply chain (Regattieri et al., 2007). Thus, RFID (Radio Frequency IDentification) becomes a powerful solution to propose a real-time access to information in order to align the SC workflow with the physical flows. However, this technology is not yet well-implemented in industry, particularly in the field of transport, due to the high economic investment it requests in comparison to others solutions, such as the bar-codes. Others barriers relate to the lack of standardized RFID protocols, to scanning problems due to interferences (relative to electromagnetic perturbations, metallic environment and nature of items) and to difficulties to implement technical solutions in real study cases in order to prove the benefits of the technology.

These technical limitations for RFID adoption should be removed by developing a distributed simulation platform to support the design and test of Decisions Support Systems (DSS) devoted to optimize RFID-based logistics systems. The platform proposed in this paper is more concerned by the control of a vehicles fleet of logistics service providers in order to demonstrate the benefits of RFID in organizing transport operations; it provides a good way to perform tests 
and validation of the main concepts that will be implemented in the development of hardware and information system required for real process execution of product delivery.

From the system point-of-view, modeling and distributed simulation should be considered as a preliminary theoretical issue of research, it assists dimensioning and validating behavior before to develop a real logistics chain management system. From this premise, we propose to focus in this article on collaborative logistics system and to define a platform composed of models for distributed simulation in the context of the Smart Products Routing project, fr. "Routage de PRODuits intellIGEnts" (PRODIGE).

The paper is organized as follows. The $\S 1$ describes the potential benefits of RFID use in SC. The $\S 2$ presents the problem statement through the description of the research project that has led us to develop a distributed simulation platform. The $\S 3$ introduces theoretical framework foundations for modeling and simulation. In $\S 4$, the discrete event models components of the platform are described. The $\S 5$ is dedicated to present the technologies used to implement the simulation in this paper. Before giving conclusions and perspectives, the authors simulate a part of the architecture to validate behaviors and discuss in $\S 6$ the results of simulation for performing validation of models and dimensioning communication network of product delivery.

\section{USE OF RFID IN SUPPLY CHAIN MANAGEMENT}

RFID is a wireless and automatic identification (auto-ID) technology, which allows the transmission of information, useful to identify items, without human intervention or physical connection (as required for bar codes reading). RFID technology is well-known in supply chain management to support the tracking of any reusable asset such as containers and pallets, and to be deployed to strengthen the enterprises ability to enhance organizational change and to manage growth in a competitive environment (Ustundag et al., 2009). However, this technology is not largely adopted by industrials, in spite of the fact that RFID is ideally believed to offer many benefits including shrinkage reduction, material handling efficiency, increased product availability, and improved assets management (Tajima, 2007). The most cited reason is the lack of returns of investment (ROI) in the short term relative to all costs required to implement RFID, such as the acquisition of tag units and readers. Technical risks, popularity of bar-codes and privacy concerns are other limits which prevent a widespread adoption of the RFID.

The existing gap between the ideal vision of RFID implementation, depicting its organizational potentialities, and its real usage in terms of defining its value-added in product-flows management has led to the emergence of two categories of scientific works; some academic researches intends to prove theoretically the benefits of RFID technology application on logistics management, as mentioned in (Sarac et al., 2010) (Dolgui et al., 2008) while technological issues of RFID deployment are discussed for small-scale systems (Ilie-Zudor et al., 2010) (Ngai et al., 2008).

This paper is concerned by these two dimensions. The proposed research deals with the technical and organisational development of RFID-based logistics systems. The implementation of RFID solutions in a real transportation case without knowing advantages and limits of these can be considered as economically risked. For this reason, we propose to develop a distributed simulation platform to define the architecture of the future system and to assess these risks.

\subsection{Intelligent products}

RFID is considered as a way to give intelligence to products. A smart product can be assimilated to an item that possesses a unique identification, that has the ability to retain or store information about itself, and that is capable to communicate with its environment including any decision support system in charge of managing it (Zaharudin et al., 2002). It also deploys a language to display its requirements and can participate to decision making concerning its own destiny. The authors clarify in particular the way to instrument this concept by placing RFID gates at any extremity of a production line, at any unloading bay used by trucks, or else at any storage zone in warehouses. They also describe how to use information carried by the product for decision making useful to optimize the supply chain performance. Nevertheless, the proposed framework remains purely theoretical, concepts and functions being not deployed in a real situa- 
tion. This notion of intelligent product is studied by other authors like (Karkkainen et al., 2003) (McFarlane et al., 2003) (Wong et al. 2002), and aims to propose a new paradigm as product-controlled systems (El Houazi et al., 2010). Thus, a community of researchers working on intelligent products has been created since several years, as (Meyer and al., 2009) prove it in their state-of-art by showing the richness of scientific production and possible applications in industry. Nevertheless, real technological solutions are not implemented in wide-scale systems like supply chains, and seem to be only tested to support job-shop control and warehouse management.

\subsection{RFID-based developments in transport}

The applications using RFID, applied to the field of transport management, focus more on the traceability and resources follow-up than on the notion of intelligent product. Most of them are concerned with the optimization of the transport activities supported by the localization of any reusable container or transport mean in order to decrease their costs. (Cheung et al., 2008) consider the assumption that GPS (Global Positioning System) / GIS (Geographic Information System) and RFID can be coupled to characterize the transport situation in real time (vehicles localization, enrichment of knowledge on the spatial distribution of routes and places to visit, identification of the routing context) and provide a theoretical solution to solve a DVRP (Dynamic Vehicles Routing Problem) devoted to a fleet of transport vehicles. (Wen, 2010) proposes an intelligent traffic management expert system comprising a passive tag, a RFID reader, a personal computer, a pair of infrared sensors, and many high-speed servers with a database system. The functions of the system include the traceability of suspicious cars concerned by traffic violations or theft, the providing of practical traffic information useful to remind congestions or to compute the shortest path between two positions in a road traffic network. (Lee et al., 2009) suggest the use of RFID in reverse logistics to count accurately the quantities of collected items in collection points. Information is then treated to schedule vehicles which transfer items and to support the locations of collection points in order to maximize the coverage of customers.

\section{THE PRODIGE PROJECT}

The PRODIGE project proposes a real framework to implement RFID in the field of road freight transport, involving a reflection on the theoretical concepts of intelligent product, product-driven system and the use of coupled information and communication technologies (ICT) and standards such as GPRS (General Packet Radio Service) and GPS. Within the project, the notion of intelligent product is limited to its ability to store and communicate information useful to support its transportation to the customers. Stored data can be codes used in the GS1 standard (GS1, 2007) to support the products traceability:

- GTIN (Global Trade Item Number),

- SSCC (Serial Shipping Container Code),

- Identification of the sender / beneficiary,

- Date of appointment,

- Sales / consumption due dates,

- $\quad$ and any information useful for logistics (Regattieri et al., 2007).

This ability also guarantees the product integrity by memorizing continuously the temperature of each product when temperature controlled transport is required.

\subsection{Technical and scientific objectives}

In this context, the purpose of the PRODIGE project is to design and implement an information chain linking up data which identify products characteristics and logistics inputs with information issue from GPS and navigation guidance tool (figure 1). The recommended technical solution includes trucks embedded computing systems, RFID tags, RFID reader with multiple antenna, GIS, ERP (Enterprise Requirement Planning) software and workflow components. Products and logistics information stored on tags are read and delivered to the embedded system through the RFID 
reader, are completed with geographical coordinates issue from GPS and send to a server dedicated to running services in charge of optimizing activities of any logistics service provider.

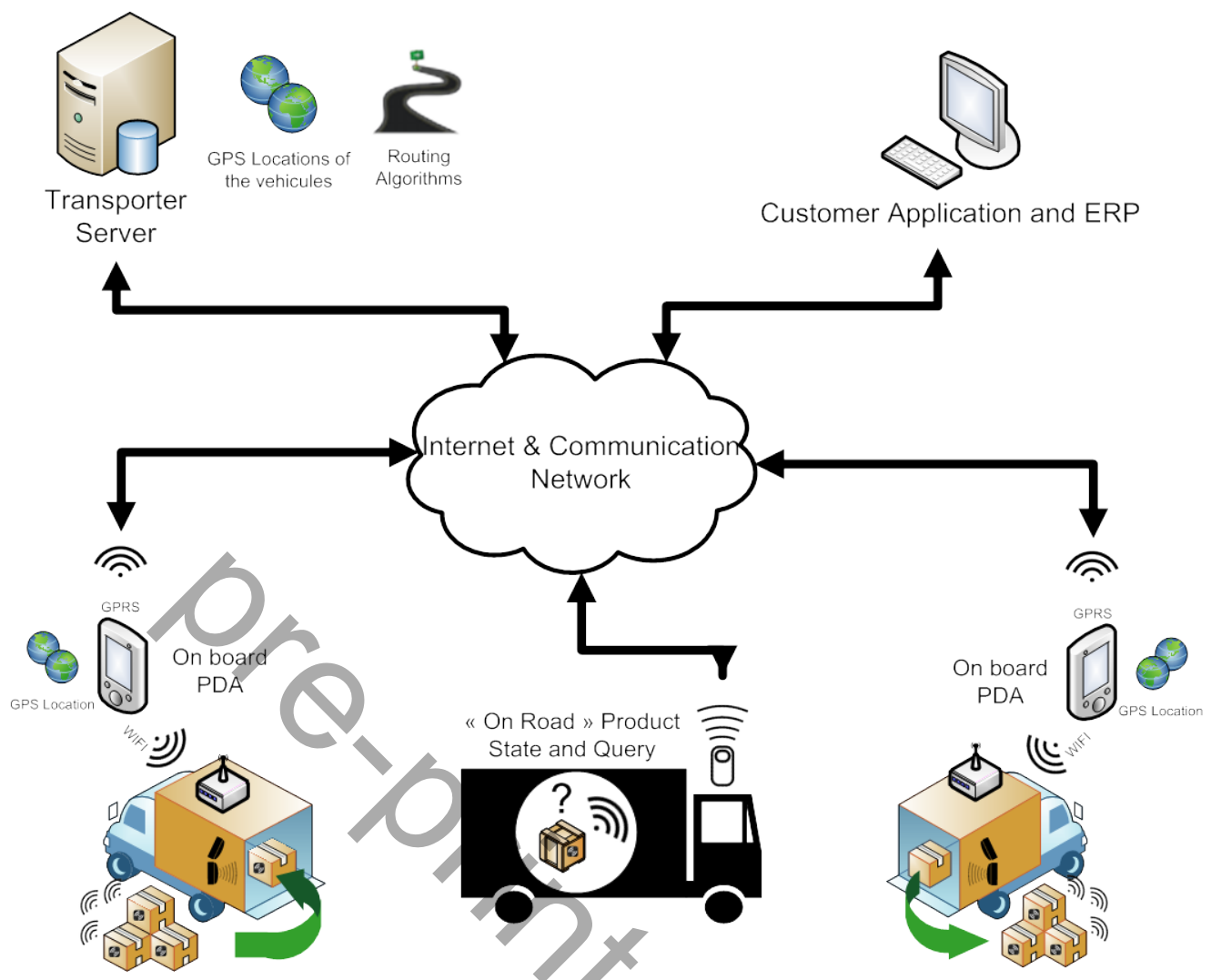

Figure 1: Communication between stakeholders

The principal technical challenge for the PRODIGE project consists in designing the RFID reader which will be embedded in the truck's trailer, others required components being purchased. The need to develop a new hardware system comes from the inappropriateness of existing readers to correctly run in environment highly disrupted such as the trailer.

In an organizational point-of-view, classical optimizers devoted to transport and fleet management focus on vehicles routing problems; innovation promoted by the project includes the development of new optimization strategies, based on information technology; they use the trace and track of any freight item loaded in vehicles at any time in order to ensure a permanent research of optimality in routing each transported item, according to:

- the current location of all the vehicles of the fleet, transmitted by wireless systems embedded in each truck to the server, so as to forecast cross-docking activities if optimization leads to assign a new vehicle to freight items (for instance, if performance may be increased, or current vehicle fails),

- the knowledge on the transportation context which can be dynamically updated (congestion, accident, exceptional weather conditions),

- $\quad$ and data characterizing the product state, such as the temperature and due dates (as mentioned before).

By applying the routing problem to products, flexibility may be gained in transport management, notably in considering non economic performances, such as on-time deliveries, carbon footprint reducing and respect of product integrity. This new organisational approach has positive impacts on collaborative logistics; by sending in advance precise logistics information, warehouse activities management will be more efficient through the preparation of cross-docking, the sizing of resources required to load / unload freight, and the control of post-cross-docking (Schaffer, 1998) (Richardson, 1999) (Gu et al., 2007). Industrial customer's performances will be increased by allowing a forecast management of customs clearance activities, a remote and permanent follow-up of loading of the trailers, especially for sensi- 
tive products such as dangerous and temperature-controlled products (Karkkainen et al., 2003). More generally, logistics systems will be dynamically reconfigured through a real time control of the routing operations, the permanent adjustment of transport / loading / unloading schedules according to the vehicles capacity optimization (Su, 1999) (Fleischmann et al., 2004) (Yang et al., 2004).

\subsection{General description of operations}

The geographical localization of in-transport products associated to information they carried (such as conditioning constraints, environment tolerance, limitation date of sale or consumption, destination) supposed to have a real impact on the routing choices. These data completed by information on current delivery course, alternative routing solutions and the analysis of the transport context (e.g. congestions, product constraints violation) need to be taken into account in the system for managing the freight routing. The use case proposed in PRODIGE Project will associate a model of RFID technology on one end with navigation guidance and planning tools run on a server at the other end.

The components that relay data between the computer server (that routes vehicles) and the product RFID are a Smartphone and a communication box connected to report product status changes. The principle to inform on products information changes consists in sticking (read/write) tags on products which communicates via RFID with an embedded station in the trailer (trailer box) through a RF-reader. Then this box, being available in each vehicle trailer used for transport, will transmit in Bluetooth mode to the on board Smartphone that will map freight information with geolocation data before sending them to a central server used by deciders in charge of planning transportation activities.

This approach will be considered as really effective only if the interoperability can be obtained between the components involved in transport activities. The solution developed in the PRODIGE project relies on the notion of distributed “intelligence”. A Tag associated to the product memorizes initial freight information. Then, software from embedded mobile station can access to store and update information relative to products characteristics, geolocation and current environment. At the end of the chain, the server can route the products, depending on planned activities and products and transportation resources status reported in near real-time; e.g. technical problems on trucks' fridges, time low-drift in delivering freight to customers, routing or/and transshipment optimization can be taken into account.

Beyond the freight routing, the perspective on such approach is the possibility to choose transportation according to sustainable development preoccupation. The better knowledge of vehicle routing can permit the use of alternative energies for powering vehicles, the choice of better sized vehicles regarding road characteristics, anticipating traffic density and legislation and adapting or grouping products by nature (e.g. frozen food, optimizing large or small volume). The first step of the project is to model the components and their communication.

\subsection{Theoretical framework to test the RFID benefits in transport}

An in-situ testing of the RFID reader prototype provided by the technical development is planned in 2012 with the support of the TSP (Transport Service Provider), member of the PRODIGE project. First discussions with the provider emphasize that real transportation situations he has to manage don't represent all the variety of logistics problems that can be found in large scale supply chains. The practical framework he offers to implement is restricted regarding the solution we want to develop, so as no transshipment, cross-docking, dispatching, storage and order-picking operations are performed. If this framework is adequate to test and validate the technical solution, information stored on tags stick on products will only be used to trace the products among their transportation and will not lead to validate new strategies in managing complex products flows situations. This weakness and limitations of the technical solution previously mentioned should not be considered as the only space of solution proposed by PRODIGE. Indeed, the first step of the project defines a theoretical framework that contains the largest possible variety of transportation management problems (i.e. operations not performed by the provider). This framework should be supported by the development of a distributed simulation platform to facilitate the design and test of any decision making process devoted to optimize RFIDbased logistics systems. 


\section{MODELING AND DISTRIBUTED SIMULATION/EXECUTION PLATFORM}

The global information chain considered in the project is schematized in figure 2 (upper part). Each distributed components' behaviour must be emulated in the simulation platform, including trucks embedded systems, product RFID, GIS, GPS , ERP and workflow components. The project's first goal is to develop a platform for modeling and simulation complex logistics systems described in figure 2 (lower part). A simulation platform is composed of a modeling tool and simulators software components that run the models on one or on several computers interconnected by a network in case of distributed simulation. It will perform the validation of the enounced concepts and a good support in defining the technical requirements before to go to the final development of the hardware and software system.

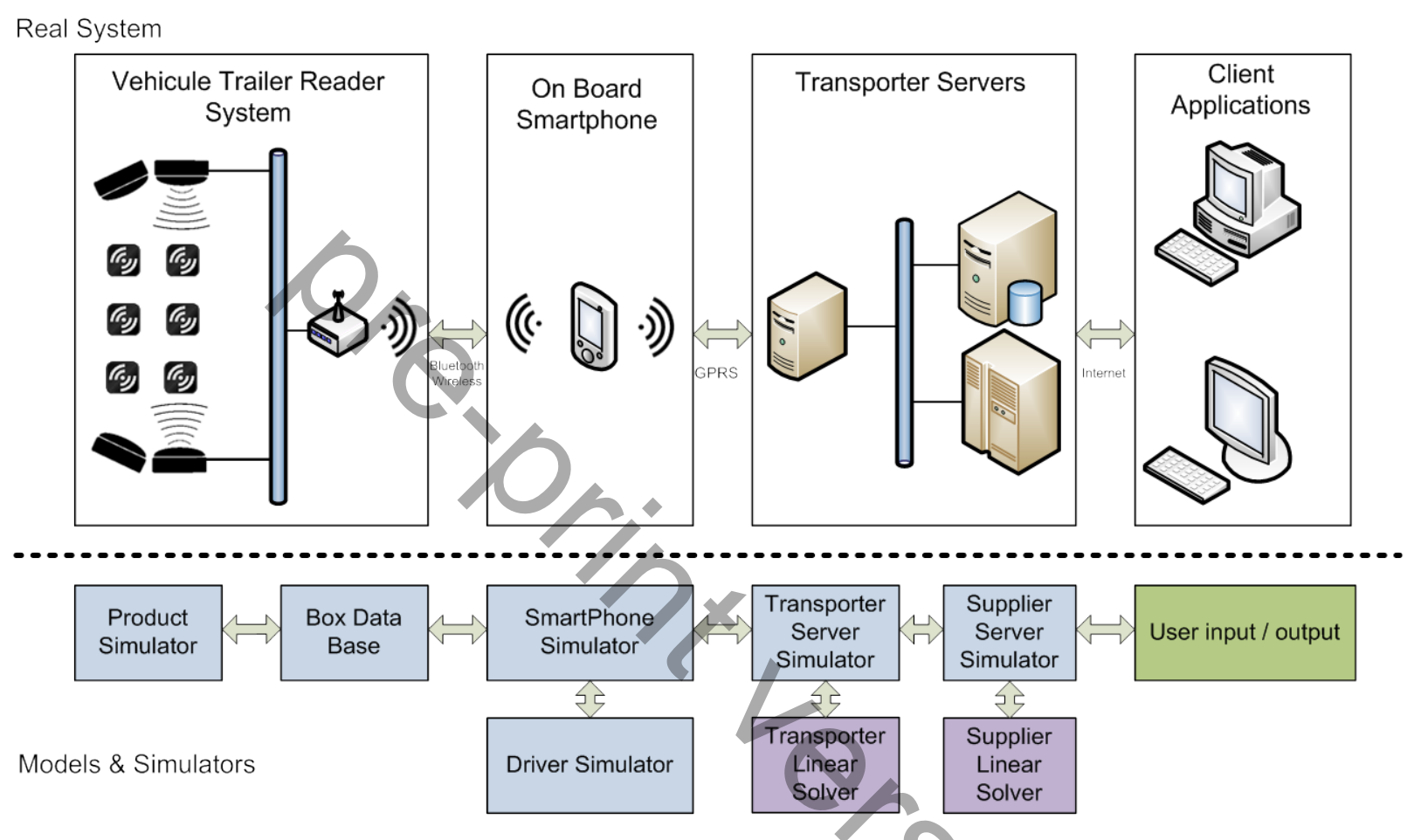

Figure 2: Information chain

Some parts of the physical system can be modeled by discrete event models and then simulated, e.g. vehicles behavior, RFID tags, workflow. Nevertheless, others parts of the system (e.g. ERP software, production planning, geolocalized vehicle routing algorithms) are usually software components frequently developed with proprietary languages. They are considered as black boxes difficult to be captured with discrete event models. To overcome this problem, it is proposed in the platform to interconnect discrete event simulation components with other heterogeneous components (e.g. linear programming) where syntactic and temporal interoperability need to be operated between those components.

After an introduction of existing platforms, the main notions relative to DEVS (Discrete EVent Specification) GDEVS (Generalized DEVS) and HLA (High Level Architecture) will be reminded; these concepts will be helpful to formalize the behavioral models for the emulated components (before describing them in details) and will establish interoperability at the execution level.

\subsection{Existing Simulation Platforms}

Despite the need of monitoring and decision support clearly identified in the field of future logistics management, there is a gap between the platform specification and implementation. The literature offers huge number of dedicated models libraries designed to be configured, connected and be managed by simulators. But few are dealing with interoperability of simulators, while heterogeneous enterprise ISs (Information System) supposed to exchange information 
over barriers of different processes and interpretations of information captured in the real world (e.g. using RFID, GPS sensors).

Many interesting research projects dealing with simulation interoperability requirements can be food for thought. The Piovra project (Zacharewicz et al., 2007) is a first example: a platform for simulation of civilian and military entity movements is proposed and permits to reproduce the crowd movement in case of civil war or terrorist attacks. The distributed simulation components can be either, simulators, GIS or sensors that communicate with the real world. In “STMicroelectronics, Rousset 2003-2008” (Zacharewicz et al., 2008), a workflow monitoring tool is proposed to manage and trigger the heterogeneous software components involved in Microelectronic production lines. As last examples, in (Bruzzone et al., 2005) and (Fan et al., 2007) the authors develop simulators for complex logistics network using artificial intelligent agents for the management of the information among the distributed supply chain.

All mentioned platforms are implemented in a distributed context (remote components over the web) and they are all using a distributed simulation standard (i.e; HLA, see §3.3.1) for managing interoperability of heterogeneous applications. In these platforms, discrete event modeling was employed to define the behavior of the components. In these platforms, discrete event modeling (e.g. DEVS formalism) was employed to define the behavior of the components. Convinced of the interest of these approaches, we trust these concepts can be reused for developing the simulation platform, support to the PRODIGE project.

\subsection{Process Formalization using DEVS or G-DEVS formalism}

Various formalisms compete for representing complex systems with discrete events modeling: e.g. state charts, Petri nets and DEVS (Zeigler et al, 2000). Among these ones, the latter is preferred for the several reasons. It can easily model complex systems. In addition, it intrinsically incorporates the time, manipulates conjoining the concepts of state and event and provides a clear operational semantics independent from models. In consequence, it constitutes an appropriate solution. Indeed research works already exist on the transformation of workflow, supply chain, logistics models into DEVS simulation models (Fan et al., 2007). In addition, further aspects of interoperability between distributed discrete event models and other software components are treated since some years, e.g. (Zacharewicz et al., 2008).

\subsubsection{DEVS}

B.P. Zeigler defined in 1973 a formal specification of real systems with discrete event entitled DEVS (Zeigler, 1976) (Discrete Event System Specification). DEVS is defined as an abstract universal formalism that is independent of implementation. An atomic DEVS model is a block with input and output ports to exchange discrete events. The behavior of the model is described by states linked by transitions. The transition is fired by receiving discrete events, which causes the current state change to a next one. In addition to major discrete event modeling techniques, DEVS presents the possibility of autonomous evolution of the model through the state time life; associated with the life extinction of the current state an internal state transition function is triggered. The real world input, output signals and states are abstracted by piecewise constant values where thresholds are considered as discrete events.

The concept of coupled models, introduced later (Zeigler et al, 2000), provides a means to build new coupled models made by reusing and connecting stored models. The DEVS simulator is explicitly specified in the formalism and permit to obtain unambiguous simulator development.

\subsubsection{G-DEVS}

G-DEVS (Generalized DEVS) emerged on the drawback that most classical discrete event models face (e.g. DEVS): they approximate observed input-output signals as piecewise constant trajectories. G-DEVS defines abstractions of information with piecewise polynomial trajectories (Giambiasi et al., 2000). Thus, G-DEVS defines the coefficientevent as a list of values representing more accurately an input-output trajectory. Therefore, a DEVS model, from the founding point of view, is a zero order G-DEVS model.

G-DEVS keeps the concept of the coupled model introduced in DEVS (Zeigler et al., 2000). Each basic model of a 
coupled model interacts with the others to produce a global behavior. The basic models are either atomic or coupled models that are already stored in the library. The model coupling is done with a hierarchical approach (owing to the closure under coupling of G-DEVS, models can be defined in a hierarchical way).

On the simulation side, G-DEVS models employ (Zeigler et al., 2000) DEVS abstract simulator that defines the simulation semantics of the formalism. The architecture of the simulator is derived from the hierarchical model structure. Processors involved in a hierarchical simulation are Simulators which animate the dynamic behavior of atomic models, Coordinators, which permit the routing of messages between coupled models, and the Root Coordinator, which ensures global simulation management. The simulation runs by sending messages between Coordinators and Simulators. GDEVS model simulation defines an event as a list of coefficient values that differs to a unique value in DEVS.

\subsection{Distributed Simulation}

The goal of distributed simulation is to use available software and hardware resources more efficiently, to provide work for remote resources and/or to reuse existing simulations (more generally systems) by interconnecting them. An efficient distributed process should manage interoperability, confidentiality, integrity and causality using temporal synchronization algorithms.

Distributed simulation strength is the capacity of exchanging information between heterogeneous distributed systems, as well as synchronizing this information for preserving the behavioral causality. It implements components to orchestrate the exchange of data between IS. This ancestor of e.g. SOA (Service Oriented Architecture) is still a robust alternative because handy at low level of code abstraction with the local behavior commonly expressed by discrete event models, such as DEVS (Zeigler, 1976). The synchronization is completely explicit using classical synchronization algorithms. The two main algorithms are the conservative Chandy-Misra algorithm, in use as e.g. in (Zacharewicz et al., 2008), or the Jefferson optimistic algorithms (Fujimoto, 2000). The performance aspect of the messages exchange, i.e. the local interpretation of messages by the simulations (model behavior) is left to local behavior and is not discussed directly by distributed simulation. First distributed systems standards as CORBA (Common Object Request Broker Architecture) were dedicated to distributed object management (including the right to read and write the object), in distributed simulation standards (e.g. HLA) time synchronization has been pushed to central concern that is particularly adapted to highly dynamic systems as logistics systems.

\subsubsection{High Level Architecture}

The HLA (High Level Architecture) (IEEE, 2000) is a standard for specification of software architecture that defines assembled software consisting of distributed simulations and applications. This standard was introduced by the DMSO (Defense Modeling and Simulation Office) of the DoD (Department of Defense). The original goal was the reuse of military applications, simulations and sensors and the development of their interoperability. In HLA, each participating application is called federate. An HLA federate interacts within an HLA federation (Federated Group). The information are exchanged trough a central execution software components entitled RTI (Run Time Infrastructure). HLA definitions have been formalized in Standards: HLA 1.3 in 1996 which was subsequently updated in HLA 1516 (IEEE, 2000). Last version of HLA: 1516 Evolved will provide web services, but its software development is still not achieved, especially the time management part.

The report on implementations of interoperable simulation (Zacharewicz et al., 2008) attests that significant enterprise solutions use HLA standard to support distributed implementation of enterprise interoperability between components at "run time" level. Numerous example of using HLA in civilian domain are annually presented in SISO (Simulation Interoperability Standardization Organization) conferences. We present below the distributed components of the PRODIGE platform that uses HLA to communicate in a System of System approach.

\section{PRODIGE PLATFORM FOR SIMULATION}

The platform is intended to manage data treatments regarding sequences of action to be performed by software re- 
sources and their time synchronization. The sequence of actions on the data is structured by the definition of a workflow model (WfMC, 1999, 2005). The synchronization is tackled by the distributed simulation synchronization algorithms developed by (Zacharewicz et al., 2005) adapted from the original Chandy-Misra conservative algorithm recalled in (Fujimoto, 2000). The proposed workflow G-DEVS models are implemented and simulated with HLA poRTIco (poRTIco, 2010).

\subsection{System of Interoperable Components}

The proposed platform for simulation (figure 3) considers different software components involved in the logistics process as HLA federates. Each component is a part of stakeholders information systems involved in the logistics chain. The partners are carriers, suppliers, customers, technical and technological solutions embedded on transport resources (vehicles) to support geolocation and permanent freight traceability. As discussed earlier, the complete system has not been modeled in G-DEVS. Some parts are already developed components ready for being interfaced and used in the platform. For instance, the tool to plan the delivery has been developed in the thesis of J. Francois using linear algebra (Francois et al., 2005). The routing algorithm for vehicle guidance system is a commercial solution (SYGIC, 2010). Both are considered as black boxes with only input output interfaces to be developed.

The use of the HLA standard supports the distributed and heterogeneous nature of the decision-making process performed along the supply chain by integrating components in federate entities. Communication of remote federates is therefore relayed by the RTI that ensures interoperability between applications used in the process. HLA also facilitates other applications to connect to the platform in the future. The proposed platform architecture integrates concepts issued from the federated interoperability (Chen et al., 2007) in order to create a flexible interfacing between components without integration and/or recoding local applications. We distinguish, in this paper, five classes of components to be involved and interconnected. We detail in the following, the different components.

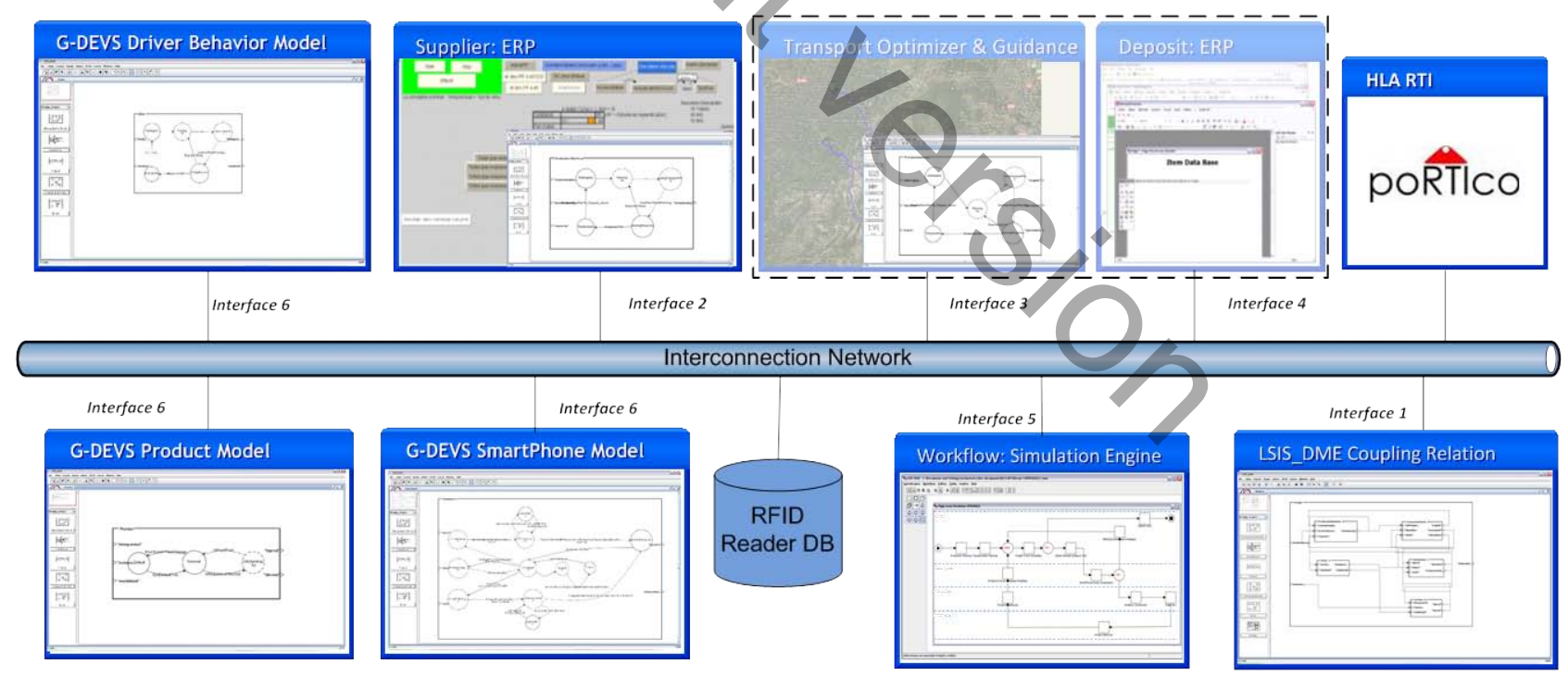

Figure 3: Simulation/Execution Platform to support the PRODIGE project

\subsection{Workflow Component}

The workflow describes the flow of information (i.e. the sequence of exchange) between the treatments (i.e. the tasks) to be performed by software resources. In more detail, this data flow between the logistics partners, the products and the client pass through the products equipped with RFID tags, the RFID readers and the Smartphone. This flow must be orchestrated by a technical component able to manage routing, sequencing and aggregating the information. The technical orchestration component is composed of a workflow engine, that dictates the proper sequence of information exchange according to a workflow model (e.g. figure 4), and a HLA RTI, that sustains the time synchronization 
regarding causality (i.e. poRTIco component in figure 3).

The WfMC (workflow Management Coalition) proposed an XML (eXtended Markup Language) representation of workflow currently accepted as a standard in workflow community (WfMC, 1999, 2005). The XML workflow process model structure correctness can be validated by referring to the WfMC workflow DTD (Document Type Definition). Nevertheless, This XML DTD is not fully convenient for the XML specification of production or logistics workflow. In detail, on the one hand, specificities of data transiting in a flow of production need to be identified in order to be handled by production software and exploited at the end of flow. On the other hand, some definitions of this DTD are only related to administrative workflow. They are not useful for the kind of workflow in our scope and can overcast the description for non workflow expert users.

Thus, (Zacharewicz et al., 2008) proposed a simple graphical language to represent the components involved in workflow dedicated to the representation of production systems. An XML workflow process model is composed of tasks components (figure 4 square items) that treat items and controllers components (figure 4 round items) that route items between tasks. Items (information, e.g. product, routing data) pass over a sequence of these components. The items are treated through the tasks completion (e.g. freight event scheduling) by resources (e.g. Server, Smartphone). We detail, in figure 4, the workflow of PRODIGE modeled with the graphical tool LSIS_WME (workflow Model Editor) developed at LSIS (Laboratory of Science of Information and Systems) of University Aix-Marseille (Zacharewicz et al., 2008). It represents the high-level workflow model of the information exchange (data flow) between different components. This model consists of an initialization task (Play symbol), an end task (Stop symbol). The figure 4 illustrates that the informational flow is initiated and finished by server component. Between those spot, several data treatment tasks are allocated to each component presented in $\S 3$, where the swim lines distinguish the responsibilities. In addition, the model contains controllers (OR-join, OR-split, etc.) to route the data between the tasks.

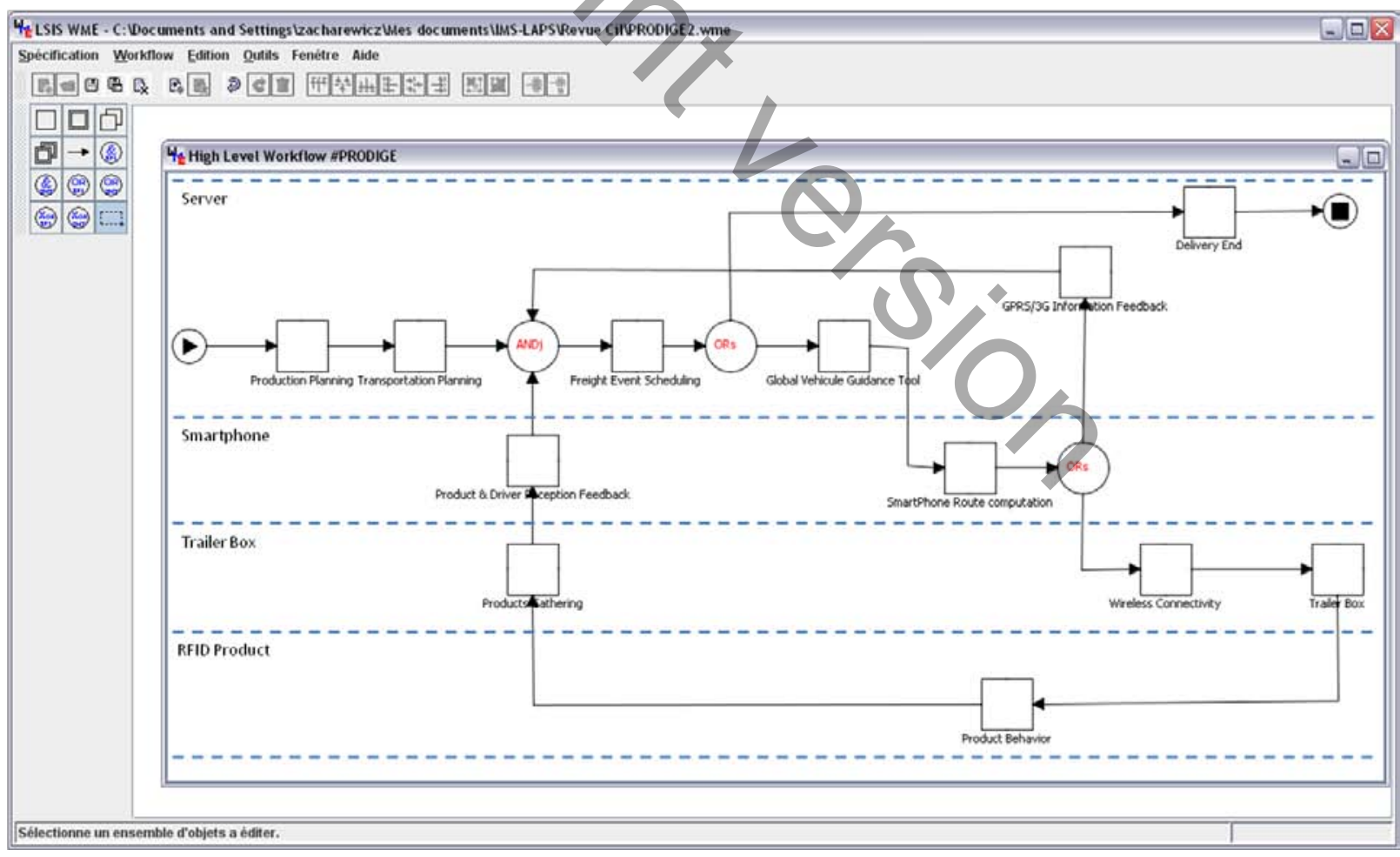

Figure 4: PRODIGE project workflow

The workflow models are high level models, so that they need to be refined for simulation. Since the beginning of workflow researches, several modeling techniques have been used to develop workflow simulation engine. Several workflow Petri nets based tools are maintained since workflow specification early time, e.g. Yasper (Yasper, 2005) and Yawl (Van Hee 2005). 
In (Zacharewicz et al., 2008), the authors have presented the functionality of LSIS_WME to generate G-DEVS specification using XML XSLT (eXtended Style Sheet Language Transformation) models transformation. In PRODIGE M\&S (Modeling and Simulation) framework, some parts of the workflow model have been transformed into a G-DEVS coupled model by coupling G-DEVS atomic models (figure 5). A library of logistics models has been proposed and the coupled model coupling relation has been generated. From the workflow model to the G-DEVS, the model has been cleared from indeterminism ambiguity and time imprecision to take advantage of the formal approach for simulation. The PRODIGE workflow model contains both G-DEVS models and other software components. The HLA interoperability permits to perform distributed simulation to validate coherence of information flow to be exchanged between the partners before real execution. Previous works experiences using HLA to ensure interoperability, mentioned in §6.1, have been reused for the application case of logistics partners.

\subsection{G-DEVS M\&S Components (workflow Subpart)}

In order to validate behavioral properties of the platform, a subpart of the workflow resources has been transformed into G-DEVS atomic and coupled models. Simulations of these models connected to other components have been run using interoperability properties of HLA distributed simulation. We present the G-DEVS coupled model in figure 5.

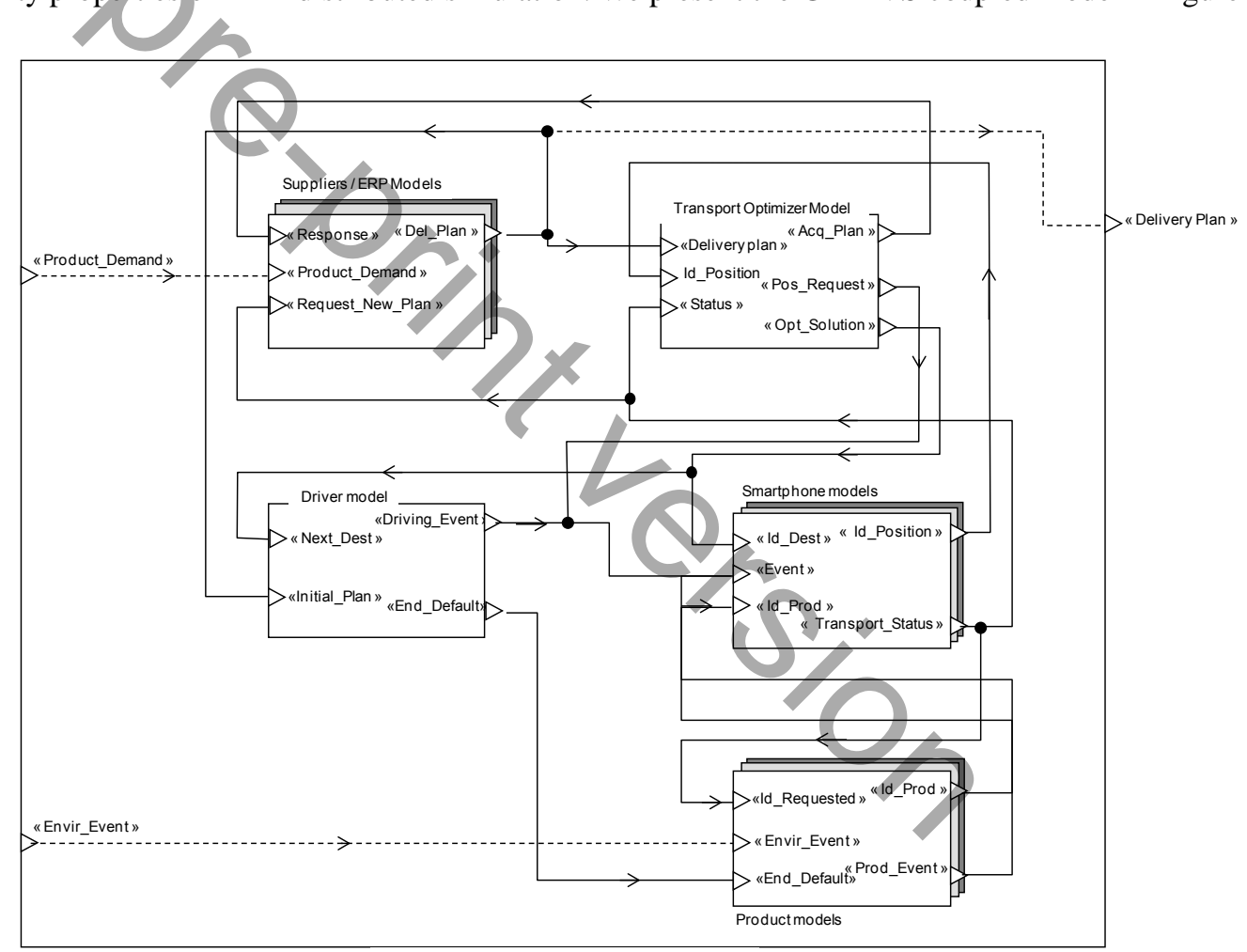

Figure 5: PRODIGE G-DEVS Coupled Model

This model is composed of G-DEVS atomic model of Transport and Driver and G-DEVS multi instance models of Suppliers, Transport Optimizer, Smartphone and Product. These last are instantiated and parameterized regarding their characteristics. The Smartphone and the Product behavior is being detailed regarding the supplier production plan and the logistics optimizer prerogatives.

The vehicle guidance component part is not under the scope of the study of this specification step, it is included in the transport optimizer model. We assume that it can generate Cartesian intermediary points for the guidance of the vehicles. Also the component "Deposit/ERP" is not modeled by G-DEVS in the simulation platform. Its behavior is expressed with a discrete event scheduler of product ordering plans. Each new plan can create competition between the demands expressed in previous iterations. The delivery plan is connected in dotted lines with the coupled model output. So far, the behavior of clients is not simulated except in the expression of the product demand plan. In the following we 
detail some of the developed G-DEVS models.

\subsubsection{Supplier / Deposit (Production Planner) Component}

This component concerns the emulation of decision making processes supported by any decision support system in charge of planning activities of any SC partner. In real situations, suppliers and deposit ERP systems will be interfaced to the developed platform in order to coordinate transportation with production plans and products status. Unfortunately, the cost for purchasing a real ERP application is expensive and it seems unrealistic to validate the simulation platform with a real tool. For this reason, we have decided to replace this system by an analytical model of planning production and delivery activities. This model is generically based on production invariants and can be implemented for representing any SC partners' planning processes (Francois et al., 2009). Each planning model can be locally parameterized and controlled, representing notably a specific behavior like the periodical decision making depending on the choice of horizon and period lengths, the use of raw of material coefficients, the definition of local costs and so on.

Computation of production plans is obtained by solving a linear programming model, depicting the constraints set to satisfy. The proposed model defines an optimal manufacturing plan under capacity constraints for storage, production and transport. Prior to formulating the mathematical model to determine an optimal planning, the following assumptions are made: (1) a supplier manages a set of resources $r$ to perform products $p$, (2) each resource has entry stocks (components storage) and exit stocks (semi-finished or finished products storage), (3) suppliers of the considered suppliers are considered as perfect (no late delivery and wrong quantity of products), (4) backorders only concern products delivered to customers. The studied planning context and assumptions are summarized in figure 6 .

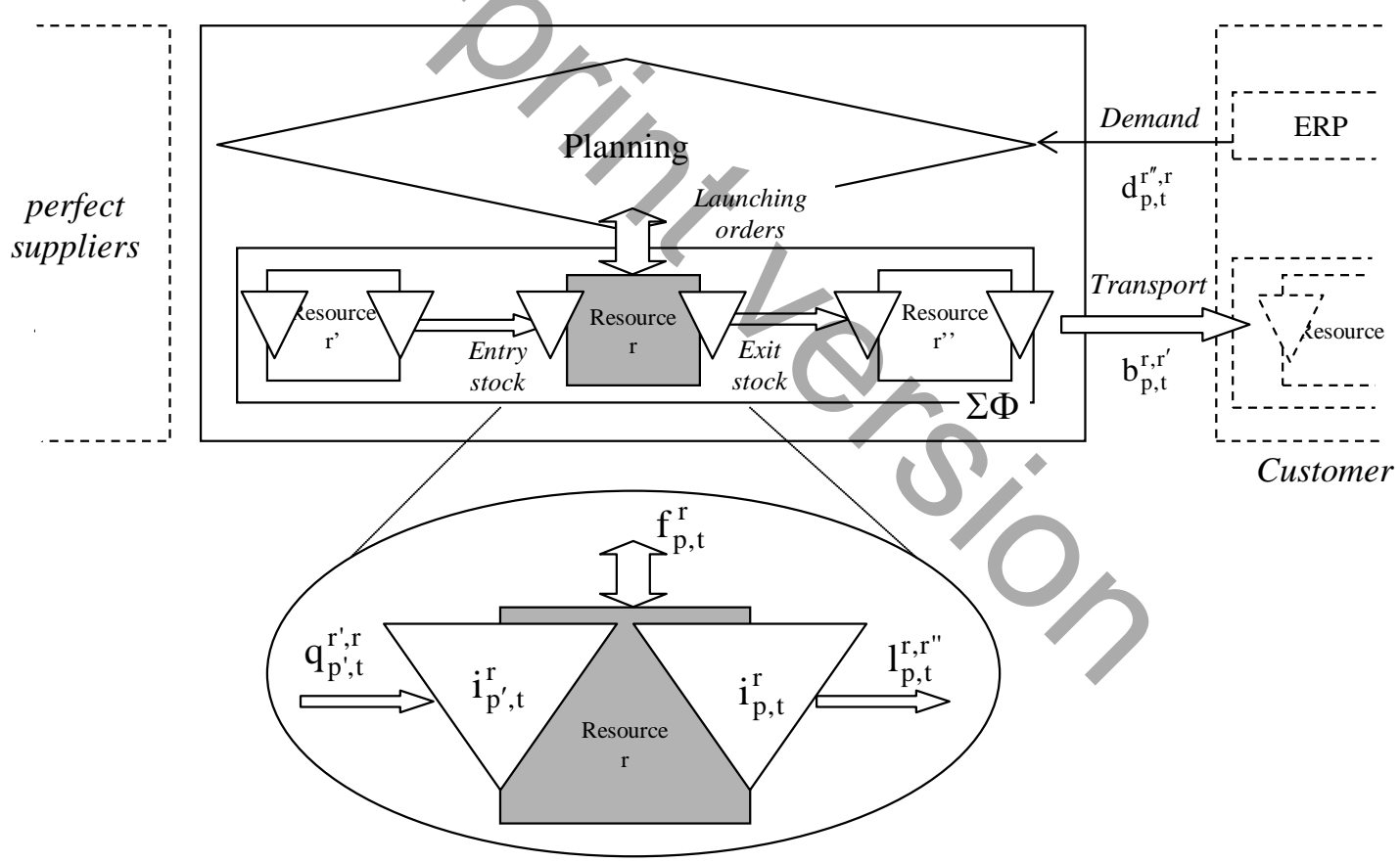

Figure 6: Supplier planning context

The analytical model is derived from (Francois et al. 2005, 2006). The whole planning horizon is split in many periods t. The set of equations (2) determines the level of product in exit stocks at the end of each period in each resource unit based on inputs (f) and deliveries (l) made during the period. The set of equations (3) calculates the level variation of entry stocks (components), in relation with bills of materials coefficients (K) and components replenishment (q). The set of equations (4) evaluates the number of products delivered late (backorder) by comparing the orderings (d) and deliveries. According to this constraint, an order not delivered by the requested date is not canceled: the model seeks to deliver the products at whatever cost, whatever the delays. The constraints (5) indicate that resources have finite capacity. The resources of production, storage and transportation are modeled by the same way. Equations (6) require the 
model to obtain a solution in which the variables are positive. Finally, the optimization criterion of the model (1) assesses the amount of storage costs, production backorder and transport delay that the model seeks to minimize.

After calculation, the model gives such a delivery plan (l) indicating the quantity of finished product to transfer from the producer to customers for each period of the horizon, and that information is sent to the transport optimizer. The plan will be converted into discrete events (described by: date, vector of variable values) and inserted into events scheduler of transport characteristics of the products (submitted to the G-DEVS model optimization transport).

The used notations and formulation of the mathematical model are then as follows:

\section{INDEXES}

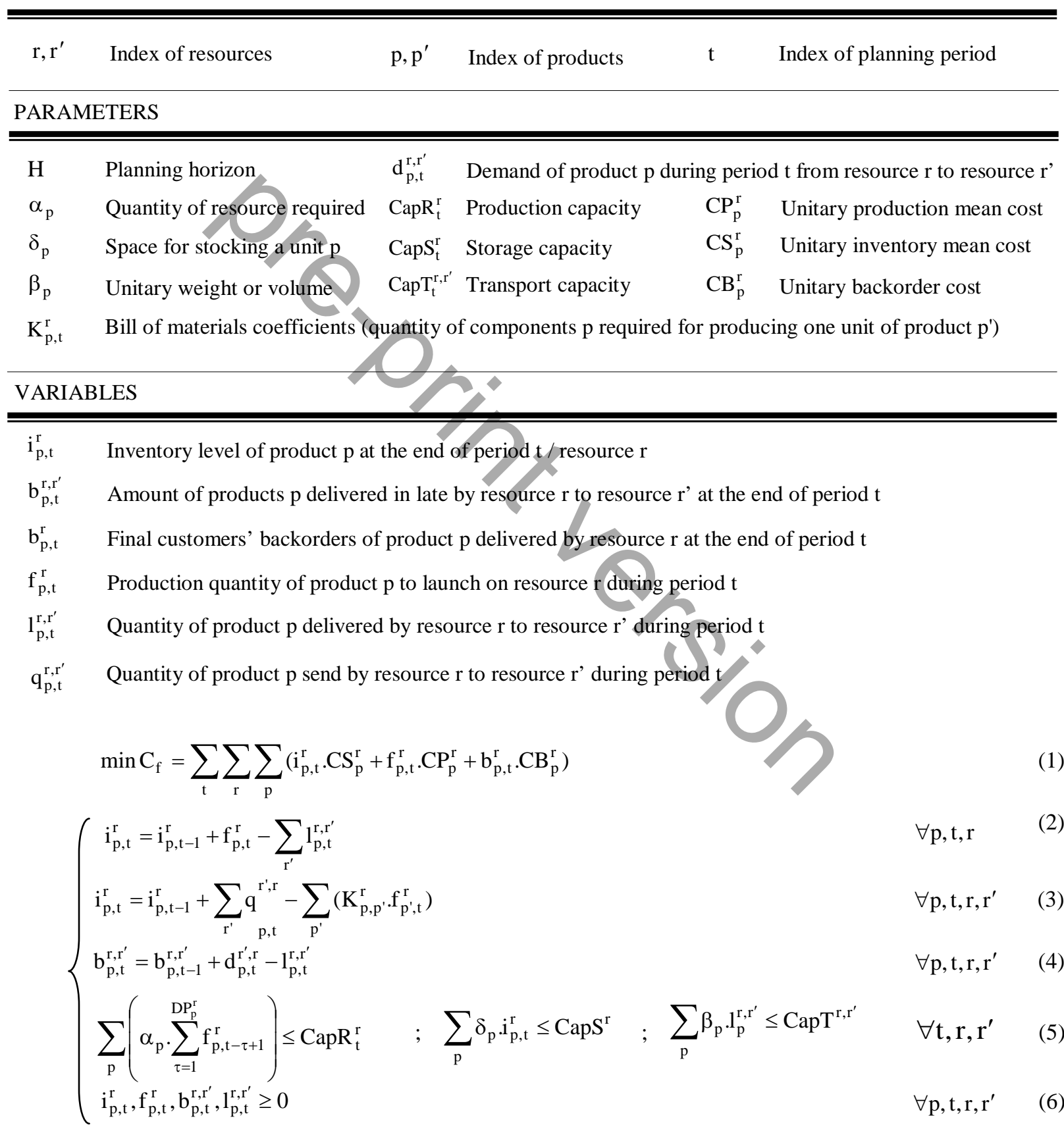

Table 1: Linear programming description

A G-DEVS model then defines the instances for planning calculation (figure 7). 


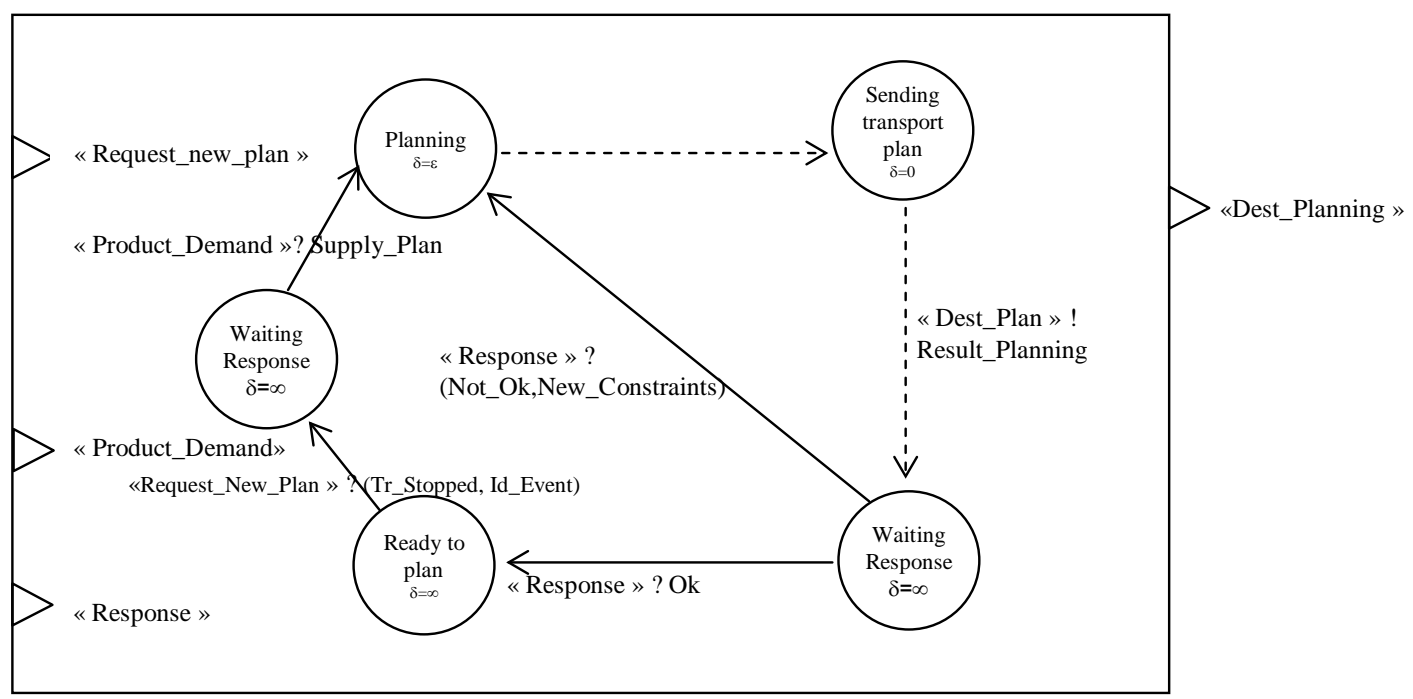

Figure 7: Supplier G-DEVS model

Indeed, in its initial state, the component is waiting for request to launch the computation of a new product delivery schedule. The shift to state Planning, triggering the search for an optimal production and delivery plan through a calculation based on linear programming, is done at the reception of an event "Request_New_Plan” received from customers (Deposit Component) or when the transportation is stopped or blocked. This situation could come from drift in the execution of activities that justify computing a new scheduling. At each recalculation, the delivery schedule is sent to the optimizer, while the transport component is placed in a pending state, waiting for new schedule response. Two cases are possible: the transportation optimizer considers the received plan applicable and the component transits to "Ready to plan" state; otherwise, it transits back to the“Planning” state, then waiting for new constraints sent by the transport optimizer.

\subsubsection{Smartphone Component}

This component is a Smartphone embedded on-board the vehicle cab. It is responsible for gathering the products information transported by the vehicle and displaying routing information for the driver. The Smartphone is querying an electronic box in the vehicle trailer using a Bluetooth 10 meters range connection to obtain the products data. Also it receives the routing orders, generated by the server and transmitted by GSM, GPRS or 3G (Third Generation) connection, for computing the vehicle's course-plotting. The products rerouting demands can be received on-road regarding the products status changes or the global delivery strategy. For instance, products being highly sensitive to their environment (e.g. frozen products, fragile products) can cause some restrictions on travel duration and road conditions. The innovation of "product driven" approach behavior is the fact that product models can warn (periodically) on detecting drift regarding its objective (e.g. while the truck is stopped). Then, this component gives periodical feedbacks concerning the product state to the server. PRODIGE research works are still investigating to combine and balance the diverging interests of the trailer's different products by filtering information locally at the Smartphone level to reduce information transmitted to the server level for computing a conciliated routing solution.

The on-board terminal is also notifying the transportation resource state. This resource can be "In Transport" (the vehicle is in motion), "in process Load” or "in process Unload”, or "Stopped” (the vehicle is stopped for any reason other than loading/unloading). This last state includes any break due to technical or legal reasons (e.g. refuel is needed or legal time devoted to drive for a day is reached) or unforeseen situations (e.g. congestion, breakdown). All state transitions are associated to an event notification describing the reason of the vehicle state change. The come back to the transportation state generates an event indicating the departure of the vehicle. The departure (on move again) events are notified internally by the Smartphone GPS (implicitly considered in figure 7, i.e. the position of the vehicle changes with time) or by the driver via the Smartphone GUI (Graphical User Interface). For instance, the restart of the truck in a 
traffic jam is not notified by the GPS or the driver under a certain minimum speed, not to oversupply the communication network. During the vehicle motion, the Smartphone can deliver on demand of the server the geo positioning of the vehicle (“D_Pos”) for displaying or recalculating the products routing.

The arrival at loading/unloading position is accomplished by comparing (with tolerance) the vehicle's current position to specific points of interest, known in advance and retrieved from a database. The movements of goods are then detected by RFID (e.g. tagged products passing through a doorway). The conformity of the unloading/loading is checked by the use of an internal variable 'nbp' regarding the number of products' units ('nbc') composing each order 'CMD'. Thus, inwards (resp. outwards) freight movements lead to increment (resp. decrement) the variable 'nbp' and compare its value to the order parameter 'nbc' (resp. to zero). The "Destination Request" state inquires about the next position to reach and the duration to go there.

The figure 8 describes the G-DEVS model of this component developed to simulate this behavior and its solicitation of the network before a real implementation of the Smartphone application.

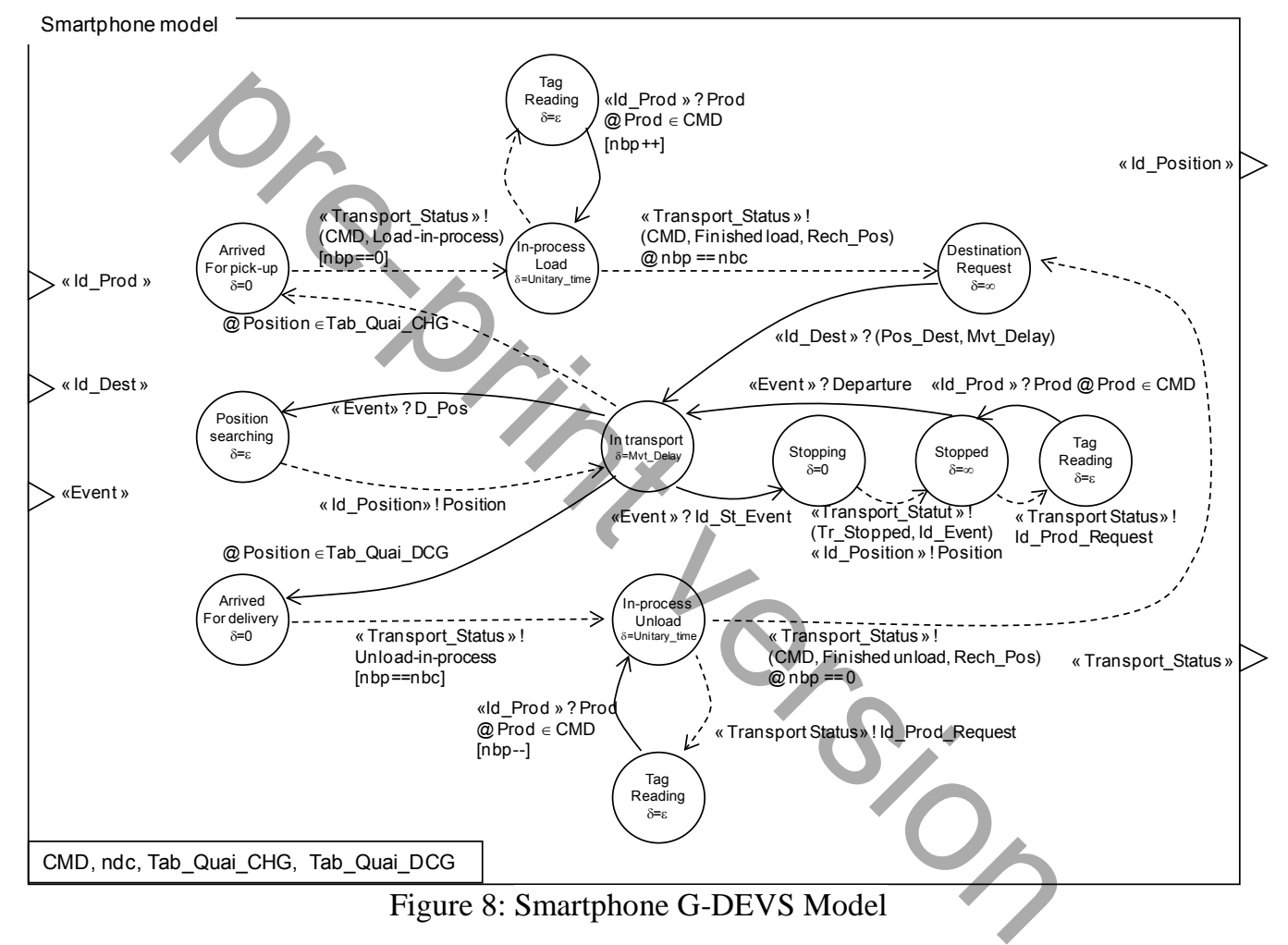

\subsubsection{Trailer Component (RFID Communication Box Component)}

PRODIGE developments includes an electronic module (trailer box) to be integrated into the vehicle trailer which is in charge of collecting data from RFID readers and sending them to the Smartphone via a wireless connection (e.g. figure 4 left part). This component is modeled as a simple "product state" database in the simulation scenarios (see in figure 2 the RFID box database). It is interfaced with the Product G-DEVS models to generate the events characterizing any product state change (position, characteristics, or environment perception such as temperature, acceleration). This base is also linked with the Smartphone G-DEVS models to notify any event issued from product status changes and to guarantee the integrity of data representing of all the transported products.

The component has been integrated as a HLA federate in the distributed simulation. The component development is based on (Zacharewicz et al., 2008) works to connect a database in HLA context. This Office Access $\subseteq$ database is linked by way of Java JDBC to poRTIco RTI in order to read/write the product properties.

\subsubsection{Product Component}

The product is initially set in a "nominal" state, i.e. the product is properly packaged and any parameter value re- 
quired to ensure the product integrity during its transportation is correct (pressure, temperature, sales due dates, etc.). It remains ready to respond to any request sent by the RFID reader in charge of seeking information on the freight status. The box can update and query information stored on the product tag; on demand, the tag send back shortly (28 kB/s) certain information (denoted "prod”) characterizing the nature of the product and any data helpful to organize the logistics (sender and recipient identity, time of delivery requested, BBD (Best Before Delivery), etc.). When information is updated on tag, the product can also query, on the way back, specific demands, such as the acceleration of the delivery process regarding its BDD. Local detection of product changes such as the packaging worsening or cold chain breaking may lead to a default state, from which the product returns to the nominal state only if checking information send from the driver is "Ok", notifying that the causes of the product default have been cleared before the product becomes spoiled.

In PRODIGE, products are supposed to be "smart”. The information describing the product has been moved to the product tag. It facilitates the relay of products information between the partners and the analysis of data characterizing the product tracking and tracing can be realized (e.g. to compute the carbon footprint). Also it can participate in monitoring the delivery process via RFID communication with the decision center (server). The RFID tags stuck on frozen, perishable or fragile products have for instance sensitive capacity to feel their environment with parameters like temperature, hygrometry, vibration, pressure or acceleration. In food industry, some works have been done to exploit the report on the condition of the product transportation (Woo et al., 2009), e.g. by analyzing subsequently the temperature data (Martinez-Sala et al., 2009). In PRODIGE, the product is intended to react dynamically, and can request a specific treatment, e.g. when the temperature increase, by finding a short pass to their delivery place, and if the pressure or vibration is too high, by finding a road that respects better these constraints or restrictions. Other works have proposed to take into account temperature for organizing dynamically the freight transportation (Abad et al., 2009).

As mentioned earlier, the product G-DEVS model can wake up when the vehicle is loaded, stopped or unloaded in order to inform about an emerging problem or a drift regarding its objectives. It can perceive a delay in the delivering process and seek periodically the server about this problem (e.g. by comparing destination place and actual place). In the model, defaults have been introduced through the probabilistic generation of perturbing events.

The G-DEVS model developed in the specification of the project is depicted in the figure 9.

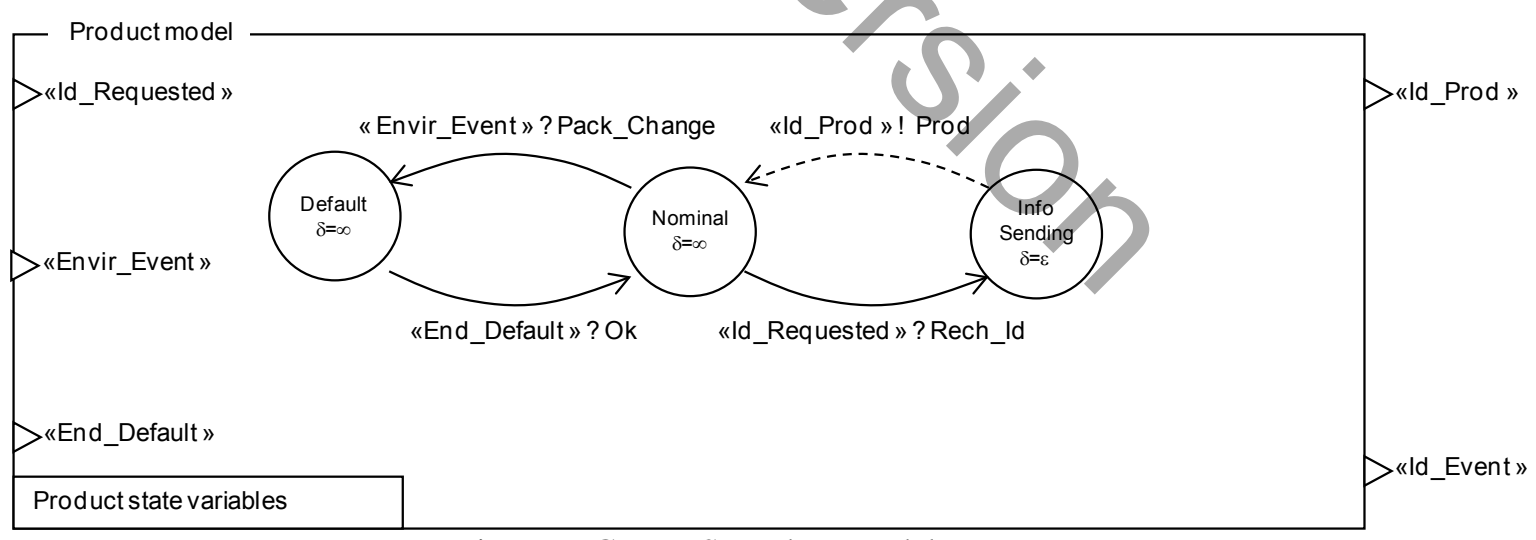

Figure 9: G-DEVS Product Model

\subsubsection{Carrier Transport Optimizer \& Routing Component}

In the final solution developed in the PRODIGE project, a GIS and a vehicles guidance device will be connected to the platform. They will include algorithms for routing vehicle regarding criteria of distance, product characteristics and most probably considerations about the impact of freight transportation on the environment.

In the simulation platform, this component is emulated by a linear planning solver inspired by (Jia et al., 2010), taking into account the physical characteristics of the products and the vehicle resource capabilities to compute the routes (set of longitude, latitude points) with intermediary points for each vehicle composing the fleet managed by the transport service provider. The idea is to define a product driven routing. In concrete terms, product orders are aggregated by 
groups to be driven to same places regarding their status (that can change at run time) acquired via RFID. The Carrier component manages a compromise between all product requirements. The communication is established by means of HLA java federate development. This component exchanges messages with other in the format of HLA XML interactions.

This behavior is still under the scope of study in PRODIGE, the testing of new strategy is up to come after having tested the architecture and the model behavior. The transportation system is treated as a planning system to be soon completed with vehicle routing problem. It will reuse existing routing algorithms and involves some specific criteria such as the dimension of the vehicles, the limitation of throughput due to the product characteristics regarding the vehicles capacity.

\subsubsection{Truck Driver model Component}

The G-DEVS Driver model is not detailed in this paper. It consists in gathering information on the delivery plan, the stock management and to duplicate them, in order to keep a reference plan (provisional optimized) to be compared to the real plan. Thus, real transportation time can be randomly defined (based on distribution laws modeling the time dispersion) to simulate the possible gap between the reference plan and the real transportation operation. This model also allows the simulation of hazards in the unfolding of transport operations such as the causes of delivery delay dispersion (e.g. congestion, technical stops too longs) or any modification in the sequences of delivery. It lastly brings information on the product state during loading/unloading or when a default state has been declared by a product.

\section{DEVELOPMENT TECHNOLOGY}

The development is performed in the Eclipse Java coding environment using an HLA simulation engine of G-DEVS model implemented from LSIS_DME (DEVS Model Editor) specifications (Zacharewicz et al., 2008). Finally the HLA RTI from the poRTIco project (poRTIco, 2010) is used for the distributed orchestration.

\subsubsection{LSIS DME}

LSIS_DME has been chosen for modeling and simulation of G-DEVS models. The reasons of this choice are the Java based development of the tool and the G-DEVS user-friendly graphical model editor. The runtime is also based on G-DEVS simulation formalism (Giambiasi et al., 2000). This tool is extended to be HLA compliant. It implements the callback functions of FederateAmbassador class for the use of RTIAmbassador to communicate with the RTI. As a result, the models are able to be simulated in a distributed environment (Zacharewicz et al., 08). LSIS_DME permits also to perform distributed simulations connected with other components (client orders event generator, Data base, guidance emulator of crossings...). A simulation engine derived LSIS_DME solution and dedicated to PRODIGE platform is being coded using the software development environment Eclipse. The elected language is Java for its portability over major operating systems, ability to develop lightweight web applications and to exchange information in XML format. LSIS_DME was originally configured to communicate with a commercial RTI. For the project, the distributed simulator is migrated to the open source poRTIco (Tu et al., 2009). The platform is running the GDEVS/HLA conservative synchronization algorithm of (Zacharewicz et al., 2005).

\subsubsection{HLA RTI Component}

The data need to be synchronized and interoperable between the different applications that exchange and treat them. For that purpose, a HLA RTI has been used. A state of art over different implementation of the HLA RTI (Run Time Infrastructure) has been realized. A choice between open source, freeware and commercial RTI solution implementation has been conducted. The RTI selected for these purpose in data exchange is poRTIco RTI (poRTIco, 2010). The main reason of this choice comes from the Java open source development of this 1.3 certified and 1516 compliant tool. poRTIco is set and parameterized under Eclipse. The FOM (Federation Object Model) file includes HLA Objects attributes to be shared. These objects are mainly products with attributes, geolocation interest / crossing points. The federates involved in the platform are both G-DEVS Models and other heterogeneous software applications. 
Finally, theoretical test sets, elaborated in cooperation with the transport service provider involved in the project, permits to validate and qualify the first version of the platform components by running simulation scenarios. The data base of trailer box is implemented as an Access Data Base. The carrier component is implemented by a java code position generator (with longitude and latitude extracted from a commercial GPS). The use of algorithm for routing and their parameterization is still under specification and development.

\section{SIMULATION RESULTS}

\subsection{Methodology}

The PRODIGE approach to build the physical platform consists in modeling, simulating and validating all the components behavior first. Each G-DEVS model is implemented using LSIS_DME, tested separately and then connected to the poRTIco HLA platform (Tu et al., 2009). In a second step, when simulation confirms a correct (regarding specifications) operating mode, the simulated component is replaced by its real counterpart. This physical component will be coupled with an HLA input output translator (i.e. a C++ or Java FederateAmbassador class) to communicate with the rest of the system via the platform interconnection network. Verification of the interoperability of the system real components is consequently done progressively.

The distributed simulation has permitted to validate strategic choice concerning the behavior of the components to be developed as software or hardware components of the final solution of PRODIGE. We detail, in the following, one strategic choice modeled and validated by means of the exploitation of the simulation results.

\subsection{Network Dimensioning Simulation tests}

The first concern of PRODIGE problem specification was to define the level of "intelligence" (the decision autonomy) of each component of the information chain presented in figure 2. For instance, the Smartphone component functionalities were required to be dimensioned regarding server and trailer box components demands. In detail, one question was about the (re)computation by the Smartphone of the routing guidance performed and transmitted by the server. The result of this specification is that all component behaviors are constrained by the network capacity to transmit in right time the amount of data to others components.

We have run different simulation scenarios for product transportation. The scenarios were including different parameterizations. The products nature was taken into account (e.g. identification, product characteristics, delivery time, best before end, etc.) as well as the environment perceived by them through the use of sensors (e.g. sensibility to temperature, vibration, pressure, etc.) in order to define the size of data they represent. The truck capacity and the size of the fleet of vehicles were also integrated in the simulation. The simulation has reported the number of messages exchanged and their size to be compared with the technical constraints of the networks. The results are reported in figure 10. The diagrams are 2D with the frequency and the size of the messages exchanged and the bit rate required. We have developed three scenarios of messages exchange and reproduced over different updates frequency policy. The blue bar represents optimistic behavior in messages exchange, red corresponding to PRODIGE nominal information exchange (mean) and green if including more perturbation messages. These data are compared with bitrates limit regarding the technology to be employed. Each technology is detailed and discussed in next sub points. 

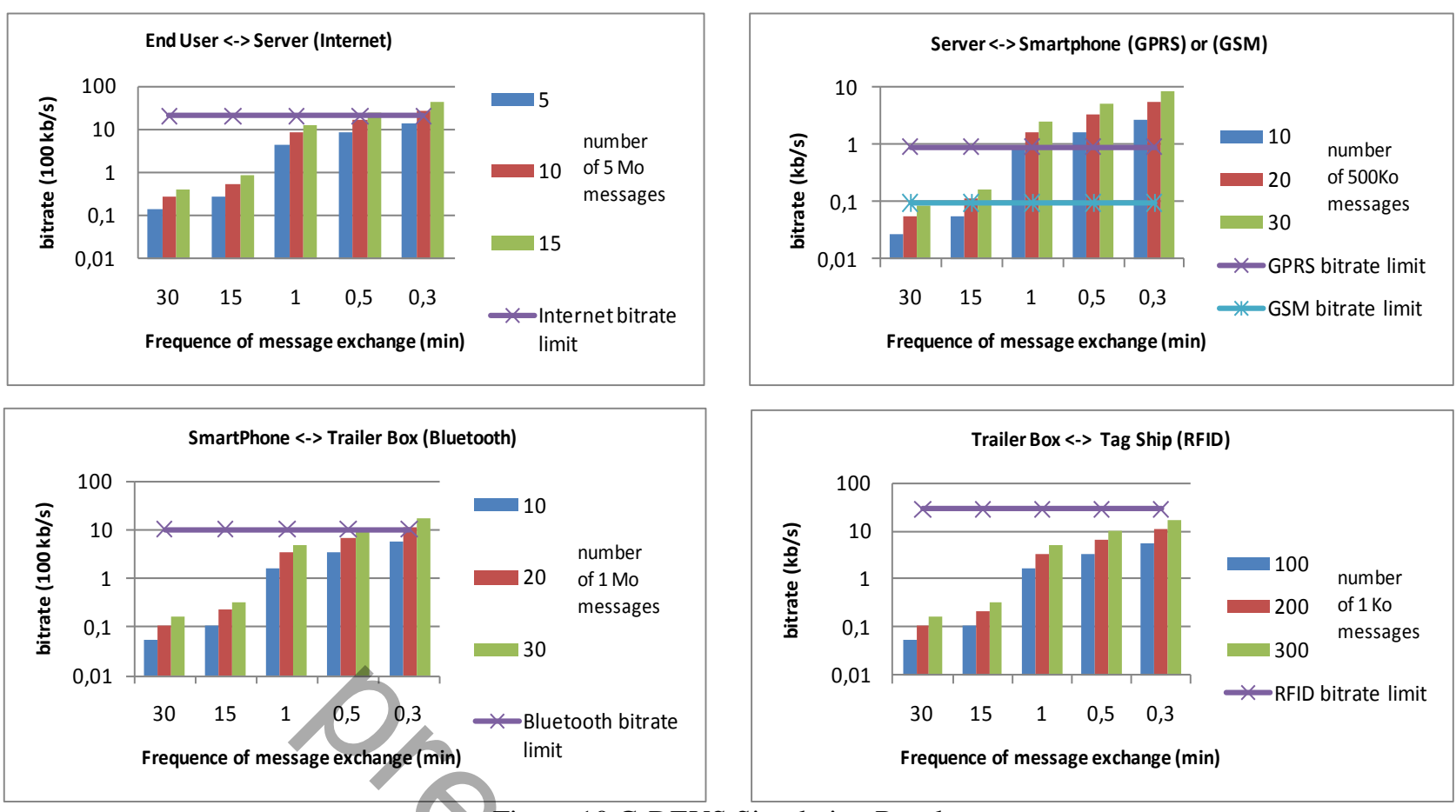

Figure 10 G-DEVS Simulation Results

\subsubsection{End User - Server Communication}

The end-user is either a client of the product or any actor of the SC. The end-user access to information is established through a web portal that displays the status of the product. The information displayed is the product description, its state regarding its environment (e.g. temperature) and its geographical location. The bit rate has been set to 2048 kB/s representing ADSL (Asymmetric Digital Subscriber Line) connections to the portal. The number of messages represents the detail on information required, here 5,15 or 15 messages has been considerate. The size of one message is 5 Mo taking into account all portal data refreshments. The simulation results show that actualization of all the data for the user can be effective every 30 seconds (less than $2500 \mathrm{kB} / \mathrm{s}$ is required for 15 messages) without risks of overheads of the network. For more frequent actualization (e.g. every 20 seconds), the access to the server can be saturated. It concludes on the capacity of the server and network to supply online (almost) real-time reports on products state and location.

\subsubsection{Server - Smartphone Communication}

The communication limits (using GPRS or GSM) between the server and the Smartphone have been compared to the data amount exchanged and the perturbation done by rerouting computations. The technologies have range of bit rate from GSM (2G) with $9.6 \mathrm{kB} / \mathrm{s}$ to UMTS (Universal Mobile Telecommunications System) (also called 3G or Third Generation) with $144 \mathrm{kB} / \mathrm{s}$. Due to restrictive availability of 3G depending on the geographical location, we have chosen to use in the simulation GSM and GPRS as a compromised high speed network (2.5G with $56 \mathrm{kB} / \mathrm{s}$ ). The size of one message has been estimated to 500 Ko for a XML file containing the aggregated products information. In the way from server to Smartphone, it has been decided to give major intermediary points in the route of the vehicle. Between those points, the vehicle can optimize locally its routing regarding in particular local parameters, e.g. traffic jam, more detailed view of the road constraints, speed limitation in order to reduce communication. In the way from product to server, the product state data are reported periodically, with only updates on states and location with a frequency that depends on the vehicle status, e.g. on road, breaks, loading and unloading. In figure 10, the saturation of GSM network is simply reached with messages exchanged every 15 minutes while GPRS allows each 1 minute exchange. The simulation results are in favor of greater local autonomy to reduce the communication. 


\subsubsection{Smartphone - Box Communication}

The Bluetooth has been elected in the communication between the Smartphone and the trailer box. The main reason is that Smartphone dispose natively of this facility. The bit rate of Bluetooth is $1 \mathrm{MB} / \mathrm{s}$ and the range is $15-20$ meters for class 2 with $2.5 \mathrm{~mW}(4 \mathrm{~dB} / \mathrm{m})$ that is considered as sufficient in covering the communication need between the trailer and the truck cabin. The simulation results conclude that all aggregated products 1 Mo messages can be transmitted; only one extreme communication case with $1.6 \mathrm{MB} / \mathrm{s}$ can saturate the Bluetooth maximum bitrate. In addition, the simulation has revealed, in the discussion to balance responsibilities between the trailer box and the Smartphone functionality, that only a basic behavior is required for the trailer box model. It is, from the model point of view, a data base, that aggregates products data before the transmission to the Smartphone. The data treatment is left to the Smartphone.

\subsubsection{Box - RFID Tag Communication}

The RFID tag has been modeled to establish the characteristics of the product description and behavior. The product is wanted to be "clever" and to participate to the logistics plan monitoring in the PRODIGE project. For this purpose, we have added some attributes in the product model: temperature limit, best-before-end and dimension information to product characteristics. So it can generate interruption when real measures go beyond the bounds defined by the interval of acceptable attributes' values and can act (indirectly) in the reorganization of delivery plan. The size of the information for one product is 10 Ko of text code. We have dimensioned 100, 200 or 300 products per trailers. We proposed to wake up the product periodically (depending also on the vehicle state) to give a report of its state regarding its environment. We defined that it can ask to accelerate its delivery in case of delay; it can also ask for bypassing some delivery points regarding its characteristics and its actûal state. We point out that all these decisions are not directly taken by the product; it simply reports on its state and then the server decides regarding the information of all the products. For instance, most urgent best before end used in medical or food industry products can lead to modify the delivery plan regarding this parameter, as well as the price negotiated with the client or the medical emergency priority. Simulation scenarios of figure 10 report that the saturation of RFID bitrate $28 \mathrm{kB} / \mathrm{s}$ is never reached even in extreme heavy communication $(16 \mathrm{kB} / \mathrm{s})$. Only real time follow up of product state is not reasonable. According to other communications constraints, a period of 1 or 15 minutes has been chosen for product report. On road, this rate can be decreased to 30 minutes. The simulation replicas have permitted to investigate, test and configure the way the product can act in the information chain without generating overload in the network. The product model is described as an object, generating interruption regarding defined context. Finally it can be considered as a small decentralized database searchable and editable by all SC partners along the SC steps.

\subsection{Simulation profits}

This work is concluded by some simulation lessons learned. First instructions are regarding reducing or controlling message exchange between the components. Erroneous (deadlock states) or not expected behaviors in the models have been also identified. These problems have been corrected in the models for securing the real development of the platform starting in the project next step.

Observations based on simulation points out that the major bottleneck of the system is the GPRS communication. In consequence the number and size of messages exchanged have been precisely tuned and bounded to prepare the development of the physical devices. Other improvements of the models are being performed with simulation feedbacks. For instance the driver behavior has been added to generate during simulation more realistic disruptions and local awareness. Nevertheless, the stochastic creation of performance deterioration events is not yet taken into account in the first scenarios of simulation.

Other limitations of the model behavior have been identified but are not yet modified in the simulation models. For instance, in the Smartphone model, the product delivery error to a client is not treated. It would be interesting to simulate the recovery of the right delivery. Also, in the Product model the transition from the "nominal" to "default" state for the product is not destructive, information is simply sent, even if the characteristics of the real product are altered irre- 
versibly.

In the actual stage of the project, a first replacement of simulated component by physical hardware, concerning the trailer box, is in-process. The HLA assures the interoperability of the simulators with physical hardware component mock-up, which has been realized using a PC with Bluetooth and RFID cards. This device is not the final component but an intermediary hardware to validate and test the functions to be integrated at the end. This PC is connected through a LAN access to the poRTIco RTI. From the modeling prescriptions, PRODIGE partners have set the trailer box hardware component to communicate with the simulation. Project partners are at the moment testing the message exchange interoperability (regarding size and frequency) between the simulation components and this physical component.

\section{CONCLUSION}

The PRODIGE project is born on the lack of technical solutions to support collaborative logistics using RFID; it intends to improve the performance of the delivery chain by using real time information on 'smart' products and road live context. The paper has presented one of the first project stages, consisting in the design of a distributed platform for simulation of complex logistics systems, in order to validate theoretical principles, functional and technical requirements before implementation in realistic situations. The logistics data flows model proposed in this paper is representing an RFID based system supporting a frequent communication between smart products and the information systems used by the stakeholders for monitoring the products transportation. The synergy between G-DEVS formalism and HLA distributed simulation standard has bridged gaps from discrete event modeling to the real system implementation by proposing a set of interconnected models progressively replaceable by real components without interrupting the HLA based information flow. The embedded workflow engine aggregates, within a system of system approach, the products transportation orders, the vehicle status and describes the data exchange flow to conciliate the vehicle routes.

This work is completed by some simulation lessons learned for dimensioning the data length and the data exchange periodicity regarding the network traffic it occurs and the bitrates it consumes in order to define the information exchange policy to be developed in the upcoming hardware and software platform. For instance, the research of the weakest link in the communication chain has identified the GPRS/GSM transmission as a bottleneck regarding the amount of data to be transmitted. The behavior of components has been, as well, tested, e.g. the balance of responsibilities between the trailer box and the Smartphone components has been evaluated. The simulation concluded to let the "clever" activities in charge of the Smartphone to reduce communications. Finally, the product component behavior has been modeled to define when it can report on drift regarding its objectives in order to act on the vehicles routing.

The discrete event simulation conclusions are currently employed to test the integration of physical components confronted to simulation elements. The development of PRODIGE platform for distributed logistics partners is promising regarding first mixed integrations of simulation and execution components both based on the "product driven" emerging concept. These works have been envisaged to be transposed to urban mobility problems that face similar problems.

\section{ACKNOWLEDGMENTS}

PRODIGE is a French National Research Agency funded project (ANR-09-VTT-09-01) Nov@log labelled.

\section{REFERENCES}

Abad, E., Palacio, F., Nuin, M., Zarate, A. G., Juarros, A., Gomez, J. M., Marco S. (2009). RFID smart tag for traceability and cold chain monitoring of foods: Demonstration in an intercontinental fresh fish logistics chain, Journal of Food Engineering 93 (4), 394-399.

Bruzzone, A.G., Mosca, R., Revetria, R., Bocca, E., Briano, E. (2005). Agent directed HLA simulation for complex supply chain modelling, Simulation, 81 (9), 647-655. 
Chen, D., Dassisti, M., Elvesæter, B. (2007). Enterprise Interoperability Framework and Knowledge Corpus - Final report Annex: Knowledge Pieces, Contract n IST-508 011, in Deliverable DI.3-Annex.

Cheung, B. K. S., Choy K. L., Li, C. L., Shi, W., Tang, J. (2008). Dynamic routing model and solution methods for fleet management with mobile technologies, International Journal of Production Economics 113 (2), 694-705.

Dolgui, A., Proth, J.M. (2008). RFID technology in supply chain management: state of the art and perspectives. in: Proceedings of the 17th World Congress, the International Federation of Automatic Control, Seoul, Korea, 4465-4475.

Fan, W., Xiao, T., Xiong, G., Guo, B. (2007). A Simulation Platform of Integrated Logistics Support System Based on HLA/DEVS, in: Springer Lecture notes in Computer Science, Proceedings of the 2006 Asia Simulation Conference, Systems Modeling and Simulation, Tokyo, Japan, 294-298.

Fleischmann, B., Gnutzmann, S., Sandvoss, E. (2004). Dynamic vehicle routing based on online traffic information. Transportation Science 38 (4), 420-433.

François, J., Deschamps, J.C., Fontan, G., Bourrieres, J.P. (2005). Assessing the impact of control architectures on Supply Chains performances, in: Proceedings of the 4th IFIP International Workshop on Performance Measurement, Bordeaux, France, CD ROM.

François, J., Deschamps, J.C., Fontan, G., Bourrieres, J.P. (2006). Collaborative planning for enterprises involved in different supply chains, in: Proceeding of the IEEE International Conference on Service Systems and Service Management, Troyes, France.

Francois, J., Okongwu, U., Deschamps, J.C., Lauras, M. (2009). How do the key determinants of a distributed planning process impact on the performance of a supply chain?, in: Proceedings of the IFIP APMS, Bordeaux, France, CD ROM.

El Houazi, H., Petin, J.F., Thomas, A. (2009). Design and validation of a product-driven control system based on a six sigma methodology and discrete event simulation, Production Planning \& Control 20 (6), 510-524.

Fujimoto, R.M. (2000). Parallel and Distributed Simulation System. Wiley Interscience, New-York.

Giambiasi, N., Escude, B., Ghosh S., (2000). G-DEVS A Generalized Discrete Event Specification for Accurate Modeling of Dynamic Systems, Transactions of the SCS International 17 (3), 120-134.

Gu, J., Goetschalck, M., McGinnis, L.F. (2007). Research on warehouse operation: A comprehensive review, European Journal of Operational Research 177 (1), 1-21.

GS1. (2007). The GS1 Traceability Standard: What you need to know, http://www.gs1.org/docs/traceability/GS1_tracebility_what_you_need_to_know.pdf

IEEE std 1516.2. (2000). IEEE Standard for Modeling and Simulation HLA - Federate Interface Specification, IEEE, New-York, USA.

Ilie-Zudor, E., Kemeny, Z., van Blommestein, F., Monostori, L., van der Meulen, A. (2010). A survey of applications and requirements of unique identification systems and RFID techniques, Computers in Industry article in Press, Corrected Proof.

Jia, Z.Z., Deschamps J.C., Dupas R. (2010). A Decentralized Approach for Coordinating Production and Transportation Planning, in: Proceedings of the IFIP International Conference on Advances in Production Management Systems (APMS'2010), Cernobbio, Como, Italy.

Karkkainen M., Holmstrom, J., Framling K., Artto K. (2003). Intelligent products - a step towards a more effective project delivery chain, Computers in Industry 50 (2), 141-151.

Lee, C.K.M., Chan T.M. (2009). Development of RFID-based Reverse Logistics System, Expert Systems with Applications 36 (5), 9299-9307. 
Martínez-Sala, A.S., Egea-López, E., García-Sánchez, F., García-Haro, J. (2009). Tracking of Returnable Packaging and Transport Units with active RFID in the grocery supply chain, Computers in industry 60 (3), 161-171.

McFarlane, D., Sarma, S., Chirn, J.L., Wong, C.Y., Ashton, K. (2003). Auto id systems and intelligent manufacturing control, Engineering Applications of Artificial Intelligence 16 (4), 365-376.

Meyer, G.G., Framling K., Holmstrom J. (2009). Intelligent Products: A survey. Computers in Industry 60 (1), $137-148$.

Ngai, E.W.T., Moon, K.K.L., Riggins, F.J., Yi, C.Y. (2008). RFID research ; An academic literature review (19952005) and future research directions, International Journal of Production Economics 112 (2), 510-520.

poRTIco. (2010). Software, http://porticoproject.org, accessed June 2010.

Regattieri, A., Gamberi, M., Manzini, R. (2007). Traceability of food products: General framework and experimental evidence, Journal of Food Engineering 81 (2), 347-356

Richardson, H.L. (1999). Cross docking: Information flow saves space. Transportation \& Distribution 40 (11), 51-54.

Sarac, A., Absi, N., Dauzeres-Peres, S. (2010). A literature review on the impact of RFID technologies on supply chain management, International Journal of Production Economics 128 (1), 77-95.

Schaffer, B. (1998). Cross docking can increase efficiency. Automatic I.D. News 14 (8), 34-37.

Su, C. (1999). Dynamic vehicle control and scheduling of a multi-depot physical distribution system, Integrated Manufacturing Systems 10 (1), 56-65.

Tajima, M. (2007). Strategic value of RFID in supply chain management, Journal of Purchasing \& Supply Management 13 (4), 261-273.

Tu Z., Zacharewicz G., Chen D. (2010). Harmonized and Reversible Development Framework for HLA Based Interoperable Application, in: Proceedings of the International Conference on Modeling and Applied Simulation part of the 7th International Mediterranean and Latin American Modelling Multiconference (I3M'10), Fez, Morocco.

SYGIC, (2010), www.sygic.com, accessed November 2010.

Ustundag, A., Tanyas, M. (2009). The impacts of Radio Frequency Identification (RFID) technology on supply chain costs, Transportation Research Part E Logistics and Transportation Review 45 (1), 29-38.

Van Hee, K., Post, R., Somers, L. (2005). Yet Another Smart Process EditoR, in: Proocedings of the European Modelling and Simulation Conference, Porto, Portugal.

Yang, J., Jaillet, P., Mahmassani H.S. (2004). Real-time multivehicle truckload pickup and delivery problems. Transportation Science 38 (2), 135-148.

Yasper. (2005). http://www.yasper.org/.

Wen, W. (2010). An intelligent traffic management expert system with RFID technology, Expert Systems with Applications 37 (4), 3024-3035.

WfMC. (1999). Workflow Management Coalition. Terminology \& Glossary. WfMC-TC-1011, 3.0.

WfMC. (2005).Workflow Management Coalition. workflow Process Definition Interface - XML Process Definition Language (XPDL), WFMC-TC-1025.

Woo, S.H., Choi, J.Y., Kwak, C., Kim, C.O. (2009). An active product state tracking architecture in logistics sensor networks, Computers in Industry 60 (3), 149-160. 
Wong, C.Y., McFarlane D., Zaharudin A., Agarwal V. (2002). The intelligent product driven supply chain, in: Proceedings of the IEEE International Conference on Systems, Man and Cybernetics (SMC'02), Hammamet, Tunisia.

Zaharudin, A., Wong, C., Garwal, V., McFarlane, D. Koh, R., Kang, Y. (2002). White Paper: The intelligent product driven supply chain, URL: http://www.ifm.eng.cam.ac.uk/automation/publications/w_papers/cam-autoid-wh-005.pdf

Zacharewicz, G., Giambiasi, N., N., Frydman, C. (2005): Improving the Lookahead Computation in G-DEVS/HLA Environment, in: The 9-th IEEE International Symposium on Distributed Simulation and Real Time Applications (DSRT 2005), Montreal, Canada

Zacharewicz, G., Frydman, C., Giambiasi, N. (2007). Mapping PIOVRA in GDEVS/HLA Environment, in: Proceedings of Society for Modeling and Simulation International 2010 Summer Simulation Multiconference (SummerSIM'07), San Diego, USA.

Zacharewicz, G., Frydman, C., Giambiasi, N., (2008). G-DEVS/HLA Environment for Distributed Simulations of workflows, Simulation 84 (5), 197-213

Zeigler, B.P. (1976). Theory of Modelling and Simulation. Editions John Wiley, New York

Zeigler, B.P., Praehofer H., Kim T.G. (2000) Theory of Modelling and Simulation. Editions Academic Press, San Diego

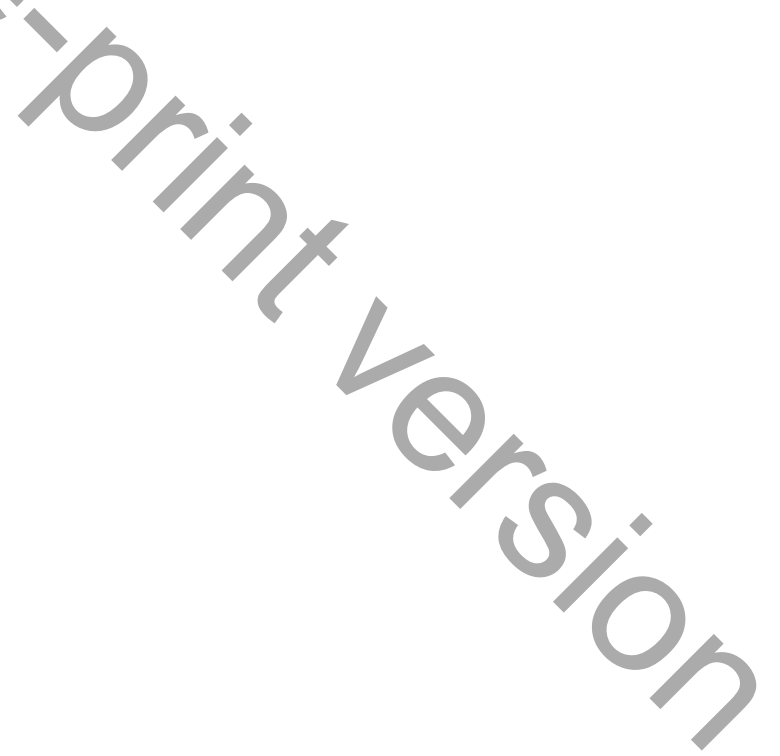

